\title{
PAR1-mediated c-Jun activation promotes heat stress-induced early stage apoptosis of human umbilical vein endothelial cells
}

\author{
SHUANG ZHANG ${ }^{1,2^{*}}$, YANAN LIU ${ }^{3 *}$, ZHENGLIAN WANG ${ }^{4 *}$, \\ JINGXIAN LIU ${ }^{1}$, ZHENGTAO GU ${ }^{5}$, QIULIN XU ${ }^{6}$ and LEI SU ${ }^{1,6}$
}

\begin{abstract}
${ }^{1}$ Department of Graduate School, Southern Medical University, Guangzhou, Guangdong 510515; ${ }^{2}$ Department of Intensive Care Unit, Jiangmen Central Hospital, Affiliated Jiangmen Hospital of Sun Yat-Sen University, Jiangmen, Guangdong 529030;

${ }^{3}$ Department of Intensive Care Unit, Nanfang Hospital, Southern Medical University, Guangzhou, Guangdong 510515;

${ }^{4}$ Department of Graduate School, Guangzhou University of Chinese Medicine, Guangzhou, Guangdong 510120;

${ }^{5}$ Department of Intensive Care Unit, The Third Affiliated Hospital of Southern Medical University, Guangzhou, Guangdong 510630; ${ }^{6}$ Department of Intensive Care Unit, General Hospital of Guangzhou Military Command, Key Laboratory of Tropical Zone Trauma Care and Tissue Repair of People's Liberation Army, Guangzhou, Guangdong 510010, P.R. China
\end{abstract}

Received December 24, 2015; Accepted February 2, 2017

DOI: $10.3892 / \mathrm{mmr} .2017 .6303$

\begin{abstract}
Our previous study indicated that when human umbilical vein endothelial cells (HUVECs), which are involved in endothelial barrier function, are heat stressed, levels of protease-activated receptor 1 (PAR1) are increased significantly. In the present study, it was demonstrated that PAR1 serves a vital role in heat stress-induced HUVEC apoptosis. When the PAR1 inhibitor, SCH79797 (SCH), or a small interfering RNA (siRNA) targeting PAR1 were used to inhibit PAR1 signaling, a marked decrease in cell apoptosis, caspase-3 activity and the expression of the pro-apoptotic protein B-cell lymphoma 2 (Bcl-2) associated X (Bax), as well as increased expression of the anti-apoptotic Bcl-2 family member, myeloid cell leukemia 1 (Mcl-1), were observed. In addition, heat stress-induced apoptosis, caspase- 3 activity and the expression of Bax were significantly increased following administration of the PAR1 agonist, TFLLR-NH2 or adenovirus overexpression of PAR1. This was accompanied by decreased protein expression levels
\end{abstract}

Correspondence to: Dr Yanan Liu, Department of Intensive Care Unit, Nanfang Hospital, Southern Medical University, 1023 Sha Tai Nan Road, Guangzhou, Guangdong 510515, P.R. China

E-mail: 123302688@qq.com

Professor Lei Su, Department of Intensive Care Unit, General Hospital of Guangzhou Military Command, Key Laboratory of Tropical Zone Trauma Care and Tissue Repair of People's Liberation Army, 111 Liu Hua Road, Guangzhou, Guangdong 510010, P.R. China

E-mail: slei_ICU@163.com

${ }^{*}$ Contributed equally

Key words: heat stress, apoptosis, protease-activated receptor 1, nuclear factor- $\kappa \mathrm{B}, \mathrm{c}-\mathrm{Jun}$ of Mcl-1. Furthermore, it was identified that the DNA binding activity of the nuclear factor (NF)- $\mathrm{B}$ p65 subunit increased and c-Jun activation was reduced as a result of inhibition of PAR1 signaling by SCH or siRNA-mediated PAR1 knockdown in heat stress-induced HUVECs. Additionally, our previous study reported that $\mathrm{NF}-\kappa \mathrm{B}$ p65 activation may have an anti-apoptosis effect on heat stressed HUVECs, whereas in the present study c-Jun activation had a pro-apoptosis effect on heat stressed HUVECs. Taken together, these results indicated that PAR1 signaling-mediated c-Jun activation promotes early apoptosis of HUVEC cells induced by heat stress.

\section{Introduction}

Previous studies using cell lines and animal models have suggested that endothelial cells are the first to be affected by heat stress injury and that severe heat stroke is prominently characterized by damaged endothelial cells $(1,2)$. In addition, a previous study demonstrated that, in the course of the acute phase response to heat stress, significant endothelial cell apoptosis may be induced (3). Although endothelial cell apoptosis appears to be important in heat stroke, the molecular mechanism underlying the induction of endothelial cell apoptosis by heat stress remains poorly understood.

Protease-activated receptor 1 (PAR1), a G protein-coupled transmembrane receptor, was first described as a high-affinity thrombin receptor (4). PAR1 is expressed on the surface of almost all cell types in the blood vessel wall, including endothelial cells, smooth muscle cells, platelets, neutrophils and macrophages. Following activation of PAR1 via proteolytic cleavage of its extracellular $\mathrm{N}$-terminus by the serine proteinase thrombin, it induces platelet activation, cell proliferation, vascular development, cell apoptosis and angiogenesis (4-6). Our previous study suggested the involvement of PAR1 in endothelial hyperpermeability in heat stress (7). However, whether PAR1 is involved in heat stress-induced endothelial cell apoptosis remains to be determined. 
Nuclear factor (NF)- $\mathrm{kB}$ signaling is associated with the transcriptional regulation of various genes involved in inflammatory responses, cell growth, survival and apoptosis $(8,9)$. Our previous study demonstrated that NF- $\mathrm{KB}$ signaling is crucial in preventing heat stress-induced apoptosis of human umbilical vein endothelial cells (HUVECs) (10). In addition, it has been reported that stimulation of PAR1, via the activation of the NF- $\mathrm{KB}$ signaling pathway, has a vital function in prostate cancer cell survival (11). However, whether PAR1 serves a role in NF- $\mathrm{kB}$ activation in heat stressed endothelial cells remains unclear. A signal-transducing transcription factor of the activating protein 1 (AP-1) family, c-Jun has been previously implicated in cell cycle progression, differentiation and cell transformation, and has been linked to apoptosis $(12,13)$. Heat stress-induced AP-1 activation in HeLa cells has been demonstrated in earlier studies (14). However, whether crosstalk between PAR, NF- $\mathrm{kB}$ and c-Jun occurs and affects endothelial cell apoptosis remains poorly understood.

The current study demonstrated that increased expression of heat stress-induced PAR1 may result in induction of B-cell lymphoma 2 (Bcl-2) associated X (Bax) expression and inhibition of myeloid cell leukemia 1 (Mcl-1) expression, which activated caspase-3 to induce apoptosis in HUVECs. The present study further clarifies the role of PAR1 in the regulation of NF- $\mathrm{KB}$ and $\mathrm{c}-\mathrm{Jun}$ activation induced by heat stress treatment. In addition, the current study demonstrated that c-Jun expression is the critical event in heat stress-induced apoptosis.

\section{Materials and methods}

Cell culture and treatment. HUVECs were purchased from the Shanghai Institute of Biochemistry and Cell Biology, Chinese Academy of Sciences (Shanghai, China). HUVECs were cultured in Dulbecco's Modified Eagle's medium (DMEM; Invitrogen; Thermo Fisher Scientific, Inc., Waltham, MA, USA) supplemented with $10 \%(\mathrm{v} / \mathrm{v})$ fetal bovine serum (FBS; Invitrogen; Thermo Fisher Scientific, Inc.), $100 \mathrm{U} / \mathrm{ml}$ penicillin (Invitrogen; Thermo Fisher Scientific, Inc.) and $100 \mu \mathrm{g} / \mathrm{ml}$ streptomycin (Invitrogen; Thermo Fisher Scientific, Inc.), at $37^{\circ} \mathrm{C}$ in a humidified atmosphere of $5 \% \mathrm{CO}_{2}$. To induce heat stress, culture dishes were placed in a circulating water bath at $37 \pm 0.5^{\circ} \mathrm{C}$ for the control group or at $43 \pm 0.5^{\circ} \mathrm{C}$ for the heat stress group, for $90 \mathrm{~min}$. Culture media were replaced with fresh media and the cells were further incubated at $37^{\circ} \mathrm{C}$ for the indicated times. HUVECs $\left(\sim 1 \times 10^{6}\right)$ were pretreated with DMSO, $40 \mu \mathrm{M}$ TFLLR-NH2 (TF; cat. no. 1464; Tocris Bioscience, Bristol, UK) for $10 \mathrm{~min}$ or $150 \mathrm{nM} \mathrm{SCH79797} \mathrm{(SCH;} \mathrm{cat.} \mathrm{no.} \mathrm{1592;} \mathrm{Tocris}$ Bioscience) for $1 \mathrm{~h}$ at $37^{\circ} \mathrm{C}$ prior to incubation at $37^{\circ} \mathrm{C}$ (control) or $43^{\circ} \mathrm{C}$ (heat stress) for $90 \mathrm{~min}$, followed by a 6 or $12 \mathrm{~h}$ recovery period at $37^{\circ} \mathrm{C}$.

Hoechst 33342 staining. HUVECs were washed with PBS three times for 2 min, stained with Hoechst $33342(1: 1,000)$ at $37^{\circ} \mathrm{C}$ for $20 \mathrm{~min}$, and subsequently washed three times with PBS for $2 \mathrm{~min}$. Images were acquired using a fluorescence microscope.

Western blot analysis. HUVECs were pretreated at $37^{\circ} \mathrm{C}$ or $43^{\circ} \mathrm{C}$ for $90 \mathrm{~min}$, and further incubated for $0,2,6$ or $12 \mathrm{~h}$.
The pre-cleaned HUVECs were homogenized in radioimmunoprecipitation buffer with phenylmethylsulfonyl fluoride (Sigma-Aldrich; Merck KGaA,Darmstadt, Germany).Following centrifugation at $14,000 \mathrm{x} g$ at $4^{\circ} \mathrm{C}$ for $10 \mathrm{~min}$, the supernatants were used for western blot analysis. Protein concentration was determined using a Bicinchoninic Acid Protein assay kit (Thermo Fisher Scientific, Inc.). Proteins (20 $\mu \mathrm{g} / \mathrm{well})$ were separated by SDS-PAGE using 10\% SDS polyacrylamide gels and transferred onto polyvinylidene difluoride membranes. Membranes were blocked with blocking solution (5\% skimmed milk diluted with PBS) at room temperature for $2 \mathrm{~h}$, followed by incubation with primary antibodies. The following primary antibodies were used: GAPDH (rabbit antibodies; dilution, 1:2,000; cat. no. ab70699; Abcam, Cambridge, MA, USA), PAR1 (rabbit antibodies; dilution, 1:2,000; cat. no. ab30961; Abcam), Mcl-1 (rabbit antibodies; dilution, 1:2,000; cat. no. ab53709; Abcam), Bax (rabbit antibodies; dilution, 1:2,000; cat. no. ab32503; Abcam), phosphorylated (p)-c-Jun (rabbit antibodies; dilution, 1:2,000; cat. no. 8222S; Cell Signaling Technology, Inc., Danvers, MA, USA), c-Jun (rabbit antibodies; dilution, 1:2,000; cat. no. 9165 p; Cell Signaling Technology, Inc.) overnight at $4{ }^{\circ} \mathrm{C}$. A horseradish peroxidase-conjugated anti-rabbit IgG antibody was used as the secondary antibody (dilution, 1:5,000; cat. no. TA130023; OriGene Technologies, Inc., Beijing, China) for incubation at room temperature for $2 \mathrm{~h}$. Antibodies were detected with Enhanced Chemiluminescence Western Blot Detection reagent (Pierce; Thermo Fisher Scientific, Inc.). Membranes were exposed to light-sensitive film and quantified using ImageJ software (version 1.3.4.67; National Institutes of Health, Bethesda, MD, USA).

Measurement of caspase 3 activity in vitro. Caspase 3 activity was determined using a caspase 3 activity assay kit, according to the manufacturer's instructions (Biovision, Inc., Milpitas, CA, USA). Briefly, the cells were lysed in caspase 3 sample lysis buffer (Biovision, Inc.). The homogenates were then centrifuged at $10,000 \times \mathrm{g}$ and $4^{\circ} \mathrm{C}$ for $10 \mathrm{~min}$ and the supernatant was collected for protein estimation using bicinchoninic acid for the caspase 3 assay. The cell lysates were then exposed to the DEVD substrate conjugate provided in the kit for $1 \mathrm{~h}$ at $37^{\circ} \mathrm{C}$. The sample was measured in an automatic microplate reader (SpectraMax M5; Molecular Devices, LLC, Sunnyvale, CA, USA) at an excitation of $400 \mathrm{~nm}$ and emission of $505 \mathrm{~nm}$.

Flow cytometric analysis of cell apoptosis using annexin $V$-fluorescein isothiocyanate (FITC)/propidium iodide (PI) staining. Cell apoptosis was analyzed with an Annexin V-FITC Apoptosis kit (Lianke Biological Engineering Co., Ltd., Zheijiang, China) according to the manufacturer's protocol. HUVECs $\left(\sim 1 \times 10^{6}\right)$ were collected, washed with ice-cold PBS and resuspended in binding buffer containing $5 \mu 1$ annexin V-FITC and $10 \mu \mathrm{l}$ PI. Following incubation at room temperature for $15 \mathrm{~min}$, samples were analyzed using a flow cytometer (FACSCanto $^{\mathrm{TM}}$ II; BD Biosciences, San Jose, CA, USA).

Small interfering (si)RNA transfection. PAR1 siRNA, c-Jun siRNA and negative control siRNA were designed and synthesized by Shanghai GenePharma Co., Ltd. (Shanghai, China). The sequences for each gene and the negative control are presented in Table I. A total of $24 \mathrm{~h}$ prior to transfection, 
HUVECs were seeded onto a 6-well plate (Nest Biotechnology Co., Ltd., Wuxi, China) at 30-50\% confluence. HUVECs were subsequently transfected with $1 \mu \mathrm{M}$ siRNAs using siRNAMate Transfection reagent (Shanghai GenePharma Co., Ltd.), according to the manufacturer's protocol. After 48-72 h, cells were collected for further experiments.

Adenoviral infection. An adenovirus (Ad) constitutively overexpressing PAR1 and empty adenovirus were constructed by ViGene Biosciences, Inc. (Rockville, MD, USA). $1 \times 10^{5}$ cells/well were infected with 100 MOI Ad in serum-free DMEM for $6 \mathrm{~h}$, following which the media was replaced with DMEM supplemented with $10 \%$ FBS.

Measurement of NF- $\kappa B$ DNA-binding capacity by enzyme-linked immunosorbent assay (ELISA). Nuclear extracts were prepared from treated and control HUVECs using a nuclear extraction kit (Active Motif, Carlsbad, CA USA; cat. no. 40410) and were performed according to the manufacturer's instructions. These extracts were then assayed determine the ability of nuclear NF- $\mathrm{B}$ p 65 to bind a DNA consensus sequence provided by an ELISA-based TransAM $\mathrm{NF}-\kappa \mathrm{B}$ p65 transcription factor assay kit (Active Motif; cat. no. 40096), according to the manufacturer's protocol.

Statistical analysis. All data were analyzed for statistical significance using SPSS software version 13.0 (SPSS, Inc., Chicago, IL, USA). Data are expressed as the mean \pm standard deviation from at least three independent experiments performed in duplicate. One-way analysis of variance was performed for multiple comparisons followed by Fisher's least significant difference post hoc comparisons. $\mathrm{P}<0.05$ was considered to indicate a statistically significant difference.

\section{Results}

Effect of heat stress on cell apoptosis and the expression levels of apoptosis-associated proteins in HUVECs. As presented in Fig. 1A, time-dependent apoptosis of HUVECs occurred following exposure to heat stress for $90 \mathrm{~min}$ and incubation for $0-12 \mathrm{~h}$. Heat stress increased the protein expression levels of Mcl-1 rapidly, and these levels were sustained for $6 \mathrm{~h}$. Following a 12-h recovery period, Mcl-1 protein expression levels decreased to baseline levels (Fig. 1B). Bax protein expression levels were increased immediately following heat stress, and experienced a further significant increase at $12 \mathrm{~h}$ (Fig. 1B). Caspase-3 activity levels followed a similar pattern (Fig. 1C).

Role of PAR1 in activating heat stress-induced apoptosis in HUVECs. Our previous study indicated that heat stress may increase PAR1 expression, a key step in disrupting endothelial barrier function in response to heat stress (7). To identify whether PAR1 engages in heat stress-induced cell apoptosis, PAR1 siRNA- or adenovirus expressing PAR1-transfected HUVECs were subjected to heat stress treatment prior to a recovery period of $12 \mathrm{~h}$. The knockdown and overexpression of PAR1 were confirmed by western blot analysis (Fig. 2A). Subsequently, flow cytometry using annexin V-FITC/PI staining was conducted to analyze the levels of apoptosis. There
Table I. Oligonucleotide sequences used in small interfering RNA experiments.

\begin{tabular}{|c|c|c|}
\hline $\begin{array}{l}\text { Target } \\
\text { gene }\end{array}$ & Primer & Sequence $\left(5^{\prime}-3^{\prime}\right)$ \\
\hline \multirow[t]{2}{*}{ PAR1 } & Sense & $\begin{array}{l}\text { GAACCCUGCUCGAAGGCUACU } \\
\text { ATT }\end{array}$ \\
\hline & Antisense & UUCUCCGAACGUGUCACGUTT \\
\hline \multirow[t]{2}{*}{ c-Jun } & Sense & GCAAACCUCAGCAACUUCATT \\
\hline & Antisense & UGAAGUUGCUGAGGUUUGCTT \\
\hline \multirow{2}{*}{$\begin{array}{l}\text { Negative } \\
\text { control }\end{array}$} & Sense & UUCUCCGAACGUGUCACGUTT \\
\hline & Antisense & ACGUGACACGUUCGGAGAATT \\
\hline
\end{tabular}

PAR1, protease-activated receptor 1 .

were increased levels of heat stress-induced apoptosis in cells overexpressing PAR1 and decreased levels following PAR1 knockdown (Fig. 2B). Following pretreatment of cells with the PAR1 agonist TFLLR-NH2 or the inhibitor SCH79797, a similar pattern was observed (Fig. 2C). These data suggested a pro-apoptotic role for PAR1 in heat stress-induced HUVEC apoptosis.

Influence of PAR1 on the expression levels of apoptosis-associated proteins. Following the demonstration that PAR1 is involved in the apoptosis of heat stress-induced HUVECs, subsequent experiments further investigated whether PAR1 influenced the protein expression levels of Mcl-1 and Bax, and caspase-3 activity. When compared with the heat stressed Ad-empty group, PAR1 overexpression significantly decreased the heat stress-induced high protein expression levels of Mcl-1 and significantly increased those of Bax at $6 \mathrm{~h}$ (Fig. 3A). In addition, PAR1 knockdown induced the opposite effect (Fig. 3B). Caspase-3 activity was significantly increased by PAR1 overexpression and was significantly decreased by PAR1 knockdown (Fig. 3C), when compared with the heat stressed Ad-empty group and NC siRNA group. Pretreatment of cells with TF significantly decreased Mcl-1 and significantly increased Bax protein expression levels (Fig. 3D). In addition, it also significantly increased caspase- 3 activity at $6 \mathrm{~h}$ when compared to the heat stressed DMSO group (Fig. 3E). Pretreatment of cells with $\mathrm{SCH}$ had the opposite effect.

Influence of PARI on $N F-\kappa B$ and $c$-Jun activation in heat stress-induced HUVECs. Our previous study reported that $\mathrm{NF}-\kappa \mathrm{B}$ signaling is crucial in preventing heat stress-induced early apoptosis (10). The present study revealed that PAR1 siRNA and its inhibitor $\mathrm{SCH}$ increased heat stress-induced activation of $\mathrm{NF}-\kappa \mathrm{B}$ (Fig. 4A). This suggested that PAR1 exerts pro-apoptotic effects via suppressing the activation of $\mathrm{NF}-\kappa \mathrm{B}$.

In Fig. 4B, a rapid increase in the protein expression levels of p-c-Jun and c-Jun was observed and these high levels were sustained for $>12 \mathrm{~h}$. The effects of PAR1 on p-c-Jun protein and c-Jun expression levels in heat stressed HUVECs 
A



B

HS (h)
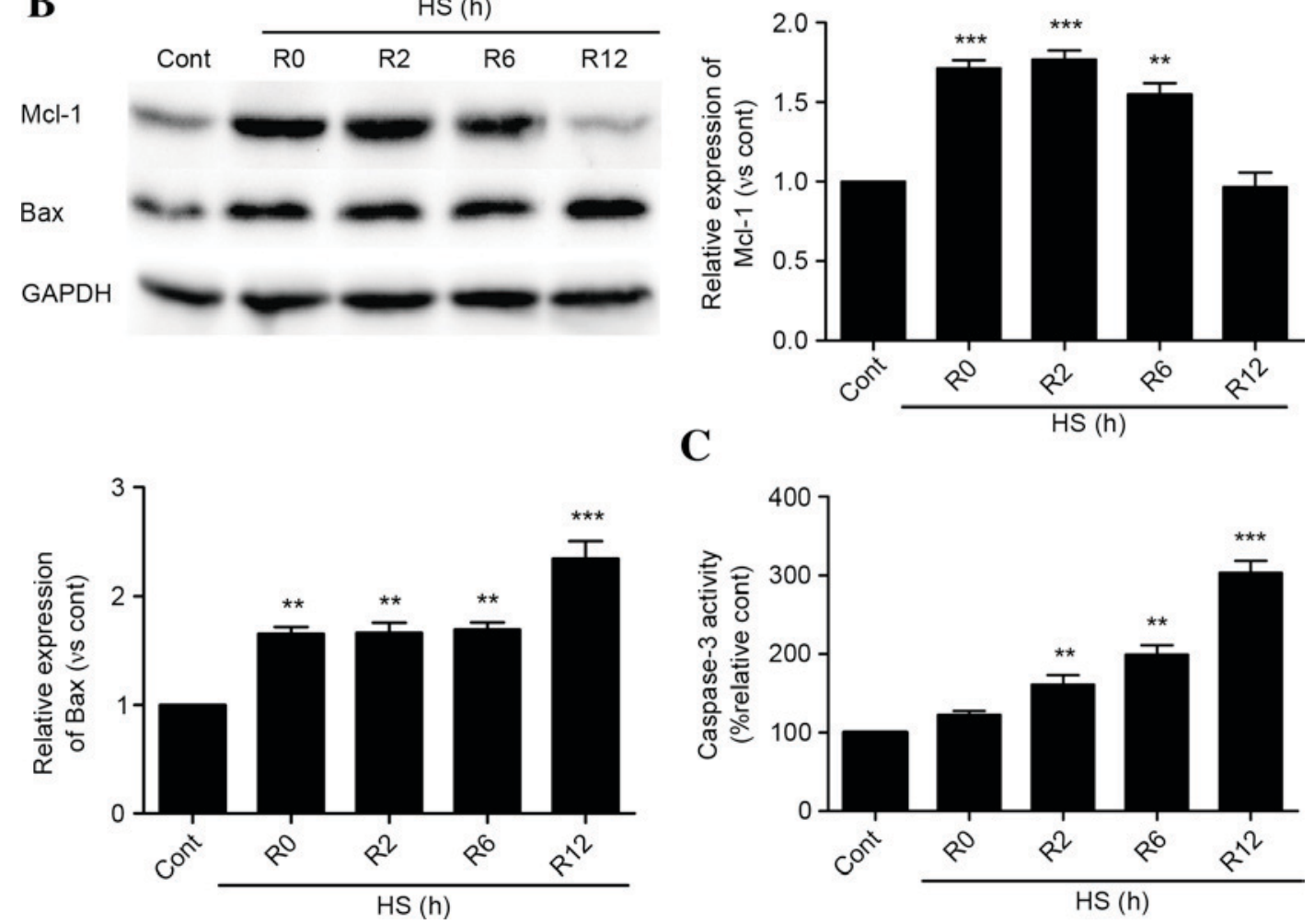

Figure 1. Effect of heat stress on apoptosis and apoptosis-associated proteins. HUVECs underwent an incubation period at $37^{\circ} \mathrm{C}$ (control) or a heat stress treatment at $43^{\circ} \mathrm{C}$ for 90 min prior to a recovery period at $37^{\circ} \mathrm{C}$ for $0,2,6$ or $12 \mathrm{~h}$. (A) After a 20 min probe with Hoechst 33342 , cells were washed. Representative images obtained using a fluorescence microscope are presented. (B) Protein expression levels of Mcl-1 and Bax were detected in HUVECs by western blotting. (C) Caspase-3 enzymatic activity was measured in cell lysates. Data are presented as a relative to the control and represent the mean \pm standard deviation of three separate experiments. ${ }^{* *} \mathrm{P}<0.01$ and ${ }^{* * *} \mathrm{P}<0.001$ vs. control. HUVECs, human umbilical vein endothelial cells; HS, heat stress; Cont, control; R, recovery time; Mcl-1, myeloid cell leukemia 1; Bax, B-cell lymphoma 2 associated X.

were additionally examined. PAR1-depleted HUVECs significantly decreased the heat stress-induced c-Jun phosphorylation and c-Jun expression levels at $6 \mathrm{~h}$ following heat stress, when compared with heat stressed NC siRNA group (Fig. 4C). Pretreatment with $\mathrm{SCH}$ reduced protein expression levels of p-c-Jun and c-Jun at $6 \mathrm{~h}$ following heat stress (Fig. 4D). These results suggested that PAR1 contributes to c-Jun activation in response to heat stress.

c-Jun is required for heat stress-induced apoptosis of HUVECs. To determine whether c-Jun is involved in heat stress-induced cell apoptosis, the effects of knockdown of c-Jun with siRNA were assessed. Successful knockdown of c-Jun was confirmed by western blot analysis (Fig. 5A). A significant suppression of apoptosis was observed following c-Jun knockdown $(\mathrm{P}<0.05$; Fig. 5B). These observations indicated that cell apoptosis induced by heat stress may be mediated by c-Jun.

\section{Discussion}

Heat stroke, a life-threatening condition characterized by a rapidly increasing core temperature to $>40^{\circ} \mathrm{C}$ and multiple organ dysfunction syndrome, is the primary cause of morbidity and mortality in heat waves. An epidemiological study reported that during heat waves in urban areas of the United States, the incidence of heat stroke varied from 17.6 to 26.5 cases per 100,000 population. The majority of people affected by classic heat stroke are very young or elderly, poor, socially isolated and do not have access to air conditioning (15). An important extracellular stimulus for heat stroke is heat stress (16). Previous studies have demonstrated that apoptosis may be significant in the pathophysiology of heat stroke (17). The endothelial cell is exposed early to heat stress injury; therefore, the mechanisms underlying endothelial cell injury and cell death are relevant to understanding the pathogenesis of heat stroke $(3,16)$. 



C


Figure 2. Role of PAR1 in heat stress-induced apoptosis in HUVECs. (A) NC siRNA, PAR1 siRNA, Ad-empty or Ad-PAR1 were transfected into HUVECs, thus achieving knockdown and overexpression of PAR, as confirmed by western blot analysis. (B) Transfected HUVECs were incubated at $37^{\circ} \mathrm{C}$ (control) or $43^{\circ} \mathrm{C}$ (heat stress) for $90 \mathrm{~min}$, followed by a 12 -h recovery period at $37^{\circ} \mathrm{C}$. Apoptosis of HUVECs was analyzed using annexin V and propidium iodide, and the percentage of early apoptotic cells (lower right quadrant) was calculated. (C) Untransfected HUVECs were pretreated with DMSO, $40 \mu \mathrm{M}$ TF for 10 min or $150 \mathrm{nM} \mathrm{SCH}$ for $1 \mathrm{~h}$ prior to incubation at $37^{\circ} \mathrm{C}$ (control) or $43^{\circ} \mathrm{C}$ (heat stress) for $90 \mathrm{~min}$, followed by a 12-h recovery period at $37^{\circ} \mathrm{C}$. Apoptosis of HUVECs was analyzed using annexin $\mathrm{V}$ and propidium iodide, and the percentage of early apoptotic cells (lower right quadrant) was calculated. Data are presented as the mean \pm standard deviation of three separate experiments. ${ }^{*} \mathrm{P}<0.05 ;{ }^{* *} \mathrm{P}<0.01$. PAR1, protease-activated receptor 1 ; HUVECs, human umbilical vein endothelial cells; NC, negative control; siRNA, small interfering RNA; Ad, adenovirus; DMSO, dimethyl sulfoxide; TF, TFLLR-NH2; SCH, SCH79797; HS, heat stress; Cont, control.

In the present study, the protein expression levels of Mcl-1 and Bax, and caspase-3 activity, were increased by heat stress in a time-dependent manner. This indicated the ability of heat stress to induce apoptosis in HUVECs. A primary finding of the current study suggested involvement of PAR1 in the apoptosis of endothelial cells following heat stress. The presented data suggested that blocking PAR1 with a specific inhibitor or siRNA results in a reduction in HUVEC apoptosis, caspase-3 activity and Bax expression, as well as an increase in Mcl-1 expression induced by heat stress. In addition, following treatment with a PAR1 agonist or overexpression of PAR1, a significant increase in heat 



$\mathrm{C}$




Figure 3. Effects of PAR1 on apoptosis-associated proteins following heat stress in HUVECs. Protein expression levels of Mcl-1 and Bax were detected by western blot analysis following transfection with (A) Ad-empty or Ad-PAR1, or (B) NC siRNA or PAR1 siRNA for $>48$ h. HUVECs were incubated at $37^{\circ} \mathrm{C}$ (control) or $43^{\circ} \mathrm{C}$ (heat stress) for $90 \mathrm{~min}$, followed by a 6-h recovery period at $37^{\circ} \mathrm{C}$. (C) Caspase- 3 enzymatic activity was measured in the cell lysates. Untransfected cells were pretreated with DMSO or $40 \mu \mathrm{M} \mathrm{TF}$ for $10 \mathrm{~min}$ or $150 \mathrm{nM} \mathrm{SCH}$ for $1 \mathrm{~h}$ prior to incubation at $37^{\circ} \mathrm{C}$ (control) or $43^{\circ} \mathrm{C}$ (heat stress) for $90 \mathrm{~min}$, followed by a 6-h recovery period at $37^{\circ} \mathrm{C}$. (D) Mcl-1 and Bax proteins were identified by western blotting analysis. (E) Enzymatic activity of caspase-3 was measured in the cell lysates. Data are presented as the mean \pm standard deviation of three independent experiments. ${ }^{*} \mathrm{P}<0.05 ;{ }^{* *} \mathrm{P}<0.01 ;{ }^{* * *} \mathrm{P}<0.001$. $\mathrm{PAR} 1$, protease-activated receptor 1; HUVECs, human umbilical vein endothelial cells; Ad, adenovirus; NC, negative control; siRNA, small interfering RNA; Mcl-1, myeloid cell leukemia 1; Bax, B-cell lymphoma 2 associated X; TF, TFLLR-NH2; SCH, SCH79797; DMSO, dimethyl sulfoxide; HS, heat stress; Cont, control.

stress-induced apoptosis, caspase- 3 activity and the expression of Bax was observed, accompanied by decreased protein expression levels of Mcl-1. These results indicated that PAR1 is involved in HUVEC apoptosis following exposure to heat stress. The Mcl-1 protein, which belongs to the Bcl-2 family of proteins, serves as an anti-apoptotic factor (18). In a previous study, a reduction of cytochrome $c$ release and caspase- 9 activation was identified in cells containing reduced levels of Bax, which suggested that HUVECs may be protected from heat stress-induced apoptosis by decreases in Bax levels (19).

The importance of NF- $\mathrm{KB}$ signaling in regulating the apoptotic program has been demonstrated in various cells (9). Our previous study suggested that the NF- $\mathrm{BB}$ signaling pathway involving HSP27, ROS and MAPK, is activated in response to heat stress, and this affords protection against 
A



B


$\mathrm{D}$


Figure 4. PAR1 is involved in NF- $\mathrm{kB}$ and c-Jun activation in heat stressed HUVECs. (A) After $48 \mathrm{~h}$ transfection with NC siRNA or PAR1 siRNA, or an $1 \mathrm{~h}$ pretreatment with DMSO or $150 \mathrm{nM} \mathrm{SCH}$, HUVECs were incubated at $37^{\circ} \mathrm{C}$ (control) or $43^{\circ} \mathrm{C}$ (heat stress) for 90 min, followed by a 6-h recovery period at $37^{\circ} \mathrm{C}$. NF- $\mathrm{kB}$ binding to DNA was quantified. (B) HUVECs underwent an incubation period at $37^{\circ} \mathrm{C}$ (control) or $43^{\circ} \mathrm{C}$ (heat stress) for $90 \mathrm{~min}$, followed by a recovery period at $37^{\circ} \mathrm{C}$ for $0,2,6$ or $12 \mathrm{~h}$. Protein expression levels of p-c-Jun and c-Jun were detected in HUVECs by western blotting. ${ }^{* * *} \mathrm{P}<0.01$ and ${ }^{* * *} \mathrm{P}<0.001$ vs. control. (C) After $48 \mathrm{~h}$ transfection with NC siRNA or PAR1 siRNA, or (D) an $1 \mathrm{~h}$ pretreatment with DMSO or $150 \mathrm{nM}$ SCH, HUVECs were incubated at $37^{\circ} \mathrm{C}$ (control) or $43^{\circ} \mathrm{C}$ (heat stress) for $90 \mathrm{~min}$, followed by a 6-h recovery period at $37^{\circ} \mathrm{C}$. Expression of p-c-Jun and c-Jun were detected by western blotting. Data are expressed as the mean \pm standard deviation of three independent experiments. ${ }^{*} \mathrm{P}<0.05 ;{ }^{* * *} \mathrm{P}<0.01 ;{ }^{* * * *} \mathrm{P}<0.001$. PAR 1 , protease-activated receptor 1 ;


dimethyl sulfoxide; HS, heat stress; Cont, control; R, recovery time; p, phosphorylated.

heat stress-induced HUVEC apoptosis (10). Previous studies have indicated that c-Jun, a signal-transducing transcription factor of the AP-1 family, is associated with apoptosis (12). In the present study, PAR1 was demonstrated to be involved in the regulation of the NF-KB signaling pathway, and PAR1 functions upstream of c-Jun to modulate its phosphorylation and protein accumulation. Furthermore, the levels of cell apoptosis markedly decreased when c-Jun-targeting
siRNA inhibited c-Jun activation. These data suggested that a pro-apoptotic pathway may be induced by PAR1 via inhibition of NF-KB and c-Jun activation.

In conclusion, the current study provides, to the best of our knowledge, the first demonstration of the potential underlying mechanism by which PAR1 expression contributes to apoptotic cell death induced by heat stress. It appears that the interactions between PAR1, NF- $\mathrm{B}$ and $\mathrm{c}$-Jun are crucial for apoptosis in 
A



B


Figure 5. Role of c-Jun in heat stress-induced cell apoptosis in HUVECs. Cells were transfected with NC siRNA or c-Jun siRNA for $>48$ h. (A) c-Jun and GAPDH protein expression levels were determined by western blot analysis. (B) Transfected HUVECs were incubated at $37^{\circ} \mathrm{C}$ (control) or $43^{\circ} \mathrm{C}$ (heat stress) for $90 \mathrm{~min}$, followed by a 12 -h recovery period at $37^{\circ} \mathrm{C}$. Apoptosis of HUVECs was analyzed using annexin $\mathrm{V}$ and propidium iodide, and the percentage of early apoptotic cells (lower right quadrant) was calculated. Data are expressed as the mean \pm standard deviation of three independent experiments. "P $<0.05$. HUVECs, human umbilical vein endothelial cells; NC, negative control; siRNA, small interfering RNA; HS, heat stress; Cont, control.

HUVEC cells; the interaction between these three proteins is worthy of further study. The results of the present study suggested that an understanding of PAR1 regulation and the underlying mechanism by which PAR1 induces cell apoptosis may lead to the development of novel strategies for treating heat-associated illness.

\section{Acknowledgements}

The present study was supported by the National Natural Science Foundation of China (grant no. 81471839) and the project team of the Natural Science Foundation of Guangdong Province (grant no. s2013030013217).

\section{References}

1. Bouchama A, Hammami MM, Haq A, Jackson J and al-Sedairy S: Evidence for endothelial cell activation/injury in heatstroke. Crit Care Med 24: 1173-1178, 1996.
2. Roberts GT, Ghebeh H, Chishti MA, Al-Mohanna F, El-Sayed R, Al-Mohanna $\mathrm{F}$ and Bouchama A: Microvascular injury, thrombosis, inflammation, and apoptosis in the pathogenesis of heatstroke: A study in baboon model. Arterioscler Thromb Vasc Biol 28: 1130-1136, 2008.

3. Brinton MR, Tagge CA, Stewart RJ, Cheung AK, Shiu YT and Christensen DA: Thermal sensitivity of endothelial cells on synthetic vascular graft material. Int J Hyperthermia 28, 163-174, 2012.

4. Hirano K and Kanaide H: Role of protease-activated receptors in the vascular system. J Atheroscler Thromb 10: 211-225, 2003.

5. Austin KM, Covic L and Kuliopulos A: Matrix metalloproteases and PAR1 activation. Blood 121: 431-439, 2003.

6. Tressel SL, Kaneider NC, Kasuda S, Foley C, Koukos G, Austin K, Agarwal A, Covic L, Opal SM and Kuliopulos A: A matrix metalloprotease-PAR1 system regulates vascular integrity, systemic inflammation and death in sepsis. EMBO Mol Med 3: 370-384, 2011.

7. Xu Q, Liu J, Wang Z, Guo X, Zhou G, Liu Y, Huang Q and Su L: Heat stress-induced disruption of endothelial barrier function is via PAR1 signaling and suppressed by Xuebijing injection. PLoS One 10: e0118057, 2015.

8. Baldwin AS: Control of oncogenesis and cancer therapy resistance by the transcription factor NF-kappaB. J Clin Invest 107: 241-246, 2001. 
9. Pahl HL: Activators and target genes of Rel/NF-kappaB transcription factors. Oncogene 18: 6853-6866, 1999.

10. Liu Y, Zhou G, Wang Z, Guo X, Xu Q, Huang Q and Su L: NF-кB signaling is essential for resistance to heat stress-induced early stage apoptosis in human umbilical vein endothelial cells. Sci Rep 5: $13547,2015$.

11. Tantivejkul K, Loberg RD, Mawocha SC, Day LL, John LS, Pienta BA, Rubin MA and Pienta KJ: PAR1-mediated NFkappaB activation promotes survival of prostate cancer cells through a Bcl-xL-dependent mechanism. J Cell Biochem 96: 641-652, 2005.

12. Bossy-Wetzel E, Bakiri L and Yaniv M: Induction of apoptosis by the transcription factor c-Jun. EMBO J 16: 1695-1709, 1997.

13. Watson A, Eilers A, Lallemand D, Kyriakis J, Rubin LL and Ham J: Phosphorylation of c-Jun is necessary for apoptosis induced by survival signal withdrawal in cerebellar granule neurons. J Neurosci 18: 751-762, 1998.

14. Stein B, Baldwin AS Jr, Ballard DW, Greene WC, Angel P and Herrlich P: Cross-coupling of the NF-kappa B p65 and Fos/Jun transcription factors produces potentiated biological function. EMBO J 12: 3879-3891, 1993.
15. Bouchama A and Knochel JP: Heat stroke. N Engl J Med 346: 1978-1988, 2002.

16. Sohal RS, Sun SC, Colcolough HL and Burch GE: Heat stroke. An electron microscopic study of endothelial cell damage and disseminated intravascular coagulation. Arch Intern Med 122: 43-47, 1968.

17. Sakaguchi Y, Stephens LC, Makino M, Kaneko T, Strebel FR, Danhauser LL, Jenkins GN and Bull JM: Apoptosis in tumors and normal tissues induced by whole body hyperthermia in rats. Cancer Res 55: 5459-5464, 1995.

18. Morciano G, Giorgi C, Balestra D, Marchi S, Perrone D, Pinotti M and Pinton P: Mcl-1 involvement in mitochondrial dynamics is associated with apoptotic cell death. Mol Biol Cell 27: 20-34, 2016.

19. Gu ZT, Li L, Wu F, Zhao P, Yang H, Liu YS, Geng Y, Zhao M and $\mathrm{Su} \mathrm{L}$ : Heat stress induced apoptosis is triggered by transcription independent $\mathrm{p} 53, \mathrm{Ca}(2+)$ dyshomeostasis and the subsequent Bax mitochondrial translocation. Sci Rep 5: 11497 , 2015. 